\title{
Does the key to treat Rheumatoid nodules lie with oncology? - Is Cisplatin an option?
}

\author{
Eisha K Omar*, Suresh Adimulam \\ From Northern and Yorkshire Deaneries Annual Rheumatology Conference \\ York, UK. 26 September 2012
}

\section{Case}

Rheumatoid nodules (RN) are not only unsightly and functionally limiting but also indicate poor prognosis in rheumatoid arthritis (RA) [1]. Treatment options are limited as traditional disease modifying antirheumatic drugs (DMARDs) like Methotrexate [2], Cyclosporine [3], Leflunomide [4] and anti TNF therapy [5,6] can make RN worse. RN can also recur after intranodular steroid injections [7] or surgical excision [8].

We report the case of a forty three year old man who was diagnosed with RA at the age of 26 years however was started on sequential DMARDS only four years later upon referral to Rheumatology, by which time RN had developed on his elbows. He was found to have seropositive, erosive RA and was started on Sulfasalazine, and a few months later oral Methotrexate and Hydroxychloroquine were added sequentially. Despite these measures, his arthritis was sub-optimally controlled and his RN continued to deteriorate.

In November 2009 he was diagnosed with head and neck squamous cell carcinoma involving his neck, nasal cavity and tongue. All DMARDs were discontinued on diagnosis. He received a six week course of Cisplatin as a single chemotherapeutic agent in Jan/Feb '10 in addition to local radiotherapy.

He noticed that his RN started to disappear during chemotherapy. His arthritis has been in complete remission after his course of cisplatin and has not noticed any recurrence of $\mathrm{RN}$ despite remaining off all DMARDs till November 2011.

\section{Discussion}

Our patient had sustained remission of RA and complete disappearance of RN with Cisplatin which has not been achieved with other treatment modalities e.g, Tacrolimus
[9] and Colchicine [10]. Although D-penicillamine has shown to be effective in treatment of RN $[11,12]$ it is not very effective in controlling RA, hence the need for further studies of Cisplatin in the management of RA and RN.

\section{Published: 14 February 2013}

\section{References}

1. Roux F, et al: Rheumatoid nodulosis. Two cases with destructive polyarthritis after 20 years. Joint, Bone, Spine 2006, 73:208-11.

2. Agarwal V, Aggarwal A: Methotrexate induced accelerated nodulosis. Journal of the Association of Physicians of India 2004, 52:538-40.

3. Spadaro A, et al: Rheumatoid nodules and cyclosporin A treatment. International Journal of Clinical Pharmacology Research 1994, 14:75-8.

4. Braun MG, et al: Development and/or increase of rheumatoid nodules in RA patients following leflunomide therapy. [German] Neuauftreten und/ oder Zunahme von Rheumaknoten unter Leflunomidtherapie bei RAPatienten. Zeitschrift fur Rheumatologie 2004, 63:84-7.

5. Spadaro A, et al: Appearance of rheumatoid nodules following antitumor necrosis factor alpha treatment with adalimumab for rheumatoid arthritis. Clinical \& Experimental Rheumatology 2007, 25:117.

6. Kekow J, et al: Development of rheumatoid nodules during anti-tumor necrosis factor alpha therapy with etanercept. Arthritis \& Rheumatism 2002, 46:843-4.

7. Baan $\mathrm{H}$, et al: Corticosteroid injections reduce size of rheumatoid nodules. Clinical Rheumatology 2006, 25:21-3.

8. Arnold C: Management of rheumatoid nodules. American Journal of Orthopedics 1996, 25:706-8.

9. Garrido-Rios A, et al: Rheumatoid nodulosis: successful response to topical tacrolimus. Clinical Rheumatology 2009, 28:1341-2.

10. Abraham Z, et al: Colchicine therapy for low-dose-methotrexate-induced accelerated nodulosis in a rheumatoid arthritis patient. Journal of Dermatology 1999, 26:691-4.

11. Dash $S$, et al: Successful treatment of methotrexate induced nodulosis with D-penicillamine. Journal of Rheumatology 1999, 26:1396-9.

12. McCarty DJ: Complete reversal of rheumatoid nodulosis. Journal of Rheumatology 1991, 18:736-7.

doi:10.1186/1471-2474-14-S1-A5

Cite this article as: Omar and Adimulam: Does the key to treat

Rheumatoid nodules lie with oncology? - Is Cisplatin an option? BMC Musculoskeletal Disorders 2013 14(Suppl 1):A5. 